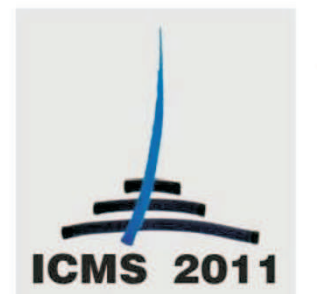

\title{
XII International Conference on Metal Structures - Wroclaw 2011
}

\section{Conference invitation}

The conference will be held in Wroclaw - Poland on 15-17 June, 2011. It is a continuation of the tradition of metal structures conferences organized by Polish Academy of Sciences, Committee for Civil Engineering, that have been taking place in Poland since 1958. The last three conferences were organized in Krakow (1995), Gdansk (2001) and Rzeszow (2006).

The conference is intended to provide a forum for discussion and exchange of experience on recent developments in the areas related to the structural behaviour and modelling, analysis and design, standardization, education, innovations, manufacturing and construction, maintenance and rehabilitation of steel, aluminium and composite structures.

We encourage all interested people and companies to apply for participation in the conference.

\section{www.icms2011.pwr.wroc.pl}

\section{Contact:}

Secretariat, ICMS 2011, Institute of Building Engineering, Wroclaw University of Technology, Wyb. Wyspianskiego 27 50-370 Wroclaw, Poland

e-mail: icms2011@pwr.wroc.pl

Tel.: (48 71) 3202365

Fax: (48 71) 3221465

Co-sponsored by

\section{IABSE}

International Association for Bridge and Structural Engineering 